\title{
Penetrating Neck Injury Evolving into Thyroid Injury with Empty Cartridge
}

\author{
Pil Young Jung \\ Department of Surgery, Yonsei university Wonju college of medicine, Wonju Severance Christian Hospital, Trauma center
}

Gunshot injury is a relatively uncommon occurrence in South Korea. Here, we present a case of neck injury caused by an empty cartridge shot.

Key Words: Gunshot wound; Neck injury; Thyroid

(Trauma Image Proced 2018(1):3-4)

\section{CASE}

A 24-year-old male with no medical history was admitted to the emergency room with penetrating neck injury caused during his Reserved Forces Military Training. The patient was shot with a sharp object into his neck from behind while he was looking at a machine gun shooting process. Upon admission, he was found to be stable with one injury on his neck. His plain X-ray and CT (Fig. 1.) demanded an emergency surgery. Accordingly, we conducted a planned subtotal thyroidectomy (Fig. 2.). The patient recovered without complications.

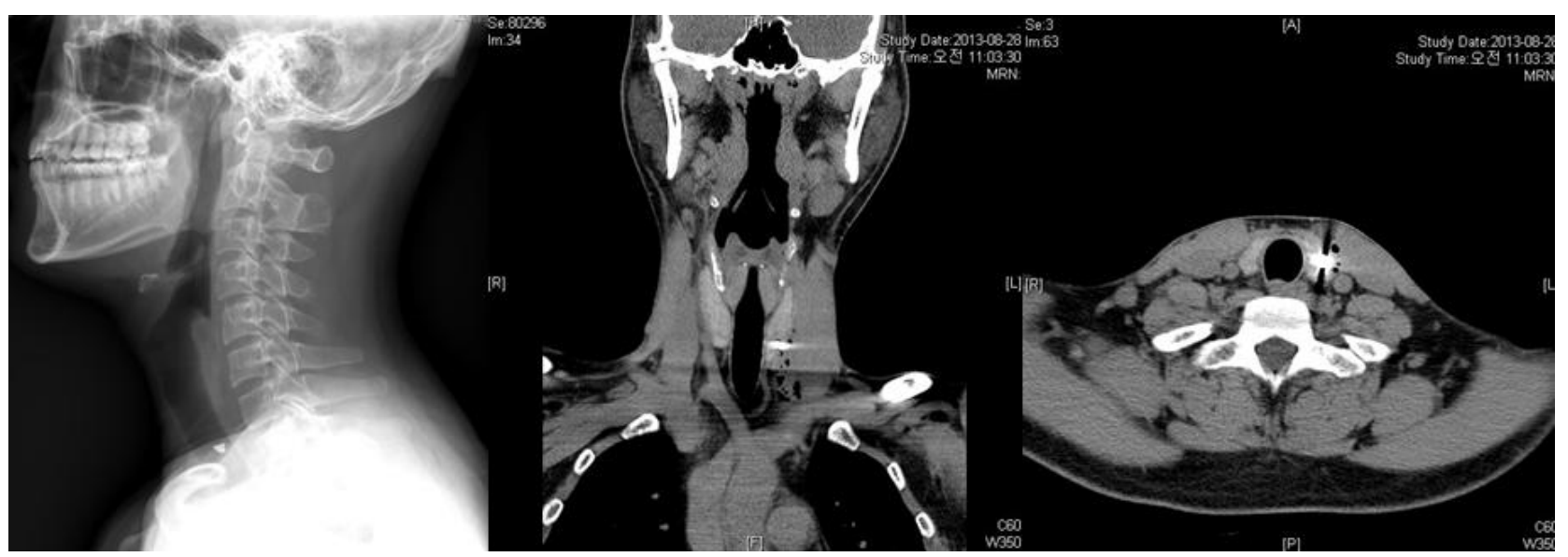

Fig. 1. Plain $\mathrm{X}$-Ray and $\mathrm{CT}$ scan showing the location of the empty cartridge

Received: April 4, 2018 Revised: May 15, 2018 Accepted: May 17, 2018

Correspondence to: Pil Young Jung, Department of Surgery, Yonsei university Wonju college of medicine, Wonju Severance Christian Hospital, 220-701, 20 IIsan-ro, Wonju-si, Gangwon-do, South Korea

Tel: 82-33-741-0882, Fax: 82-33-741-0574, E-mail: surgery4trauma@yonsei.ac.kr

Copyright (c) 2018 Korean Association for Research, Procedures and Education on Trauma. All rights reserved.

@This is an open-access article distributed under the terms of the Creative Commons Attribution Non-Commercial License (http://creativecommons.org/ licenses/by-nc/4.0) which permits unrestricted noncommercial use, distribution, and reproduction in any medium, provided the original work is properly cited 


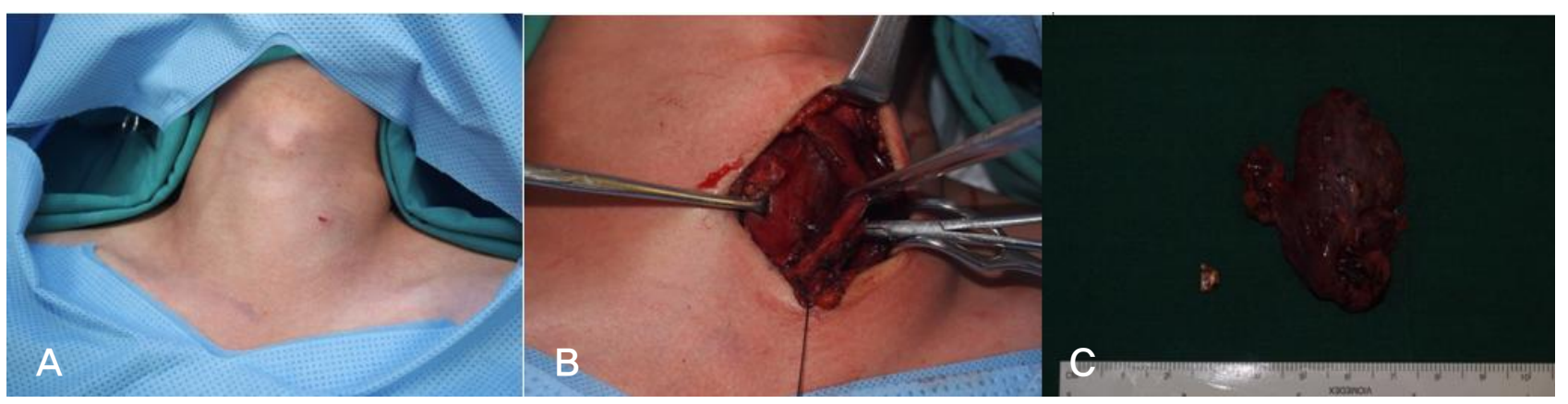

Fig. 2. (A) An external finding. The opening of the Gunshot wound is shown. (A) Surgical findings of a left thyroid injury (C) Specimen after subtotal thyroidectomy

\section{DISCUSSION}

The characteristic of a wound caused by a gunshot injury depends on the characteristics of bullet yawing, the position, and the section of the wound ballistics or profile (1). Although gunshot injury is a rare event in South Korea, proper management is mandatory for handling future cases.

\section{Conflict of Interest Statement}

No potential conflict of interest relevant to this article was reported.

\section{REFERENCE}

1. Peonim V, Srisont S, Udnoon J, Wongwichai S, Thapon A, Worasuwannarak W. Entrance and exit wounds of high velocity bullet: An autopsy analysis in the event of dispersing the mass rally in Bangkok Thailand, May 2010. Legal medicine. 2016;23:10-6. 